\title{
Misoprostol: An Essential Drug in Reproductive Health
}

\author{
Anibal Faúndes* \\ Department of Obstetrics and Gynecology, Faculty of Medical Science. State University of Campinas, Sao Paulo, Brazil
}

\begin{abstract}
Soon after misoprostol was registered for its use for the treatment of peptic ulcer in the second half of the 1980s, its application in reproductive health was progressively explored and three decades later has become an important instrument for the reproductive health care of women, although the pharmaceutical industry is still reluctant to register and inform about such application. Both the WHO and FIGO has prepared detailed instructions for its different applications in reproductive health, but their publication is either too long and detailed or assume that the reader already have a basic knowledge. With the intention of providing the basic information required for the safe use of this drug, the fundamental recommendations that the busy practitioner needs for induction of labor, late fetal demise, missed abortion, first and second trimester termination of pregnancy, incomplete abortion and prevention and treatment of postpartum hemorrhage are briefly described.
\end{abstract}

\section{Introduction}

Misoprostol is an analogue of prostaglandin E1 (PG E1), which was registered in many countries under the name of Cytotec (Pharmacia), for the treatment of peptic ulcers, particularly those caused by nonsteroidal anti-inflammatory drugs [1,2]. Misoprostol is still not registered for reproductive health indications, in many countries, meaning that the pharmaceutical industry does not produce the drug in the appropriate dosages and formulations for its use in obstetrics and gynecology and do not provide information on appropriate dosages and route of administration for its use in Obstetrics and Gynecology.

With the purpose of providing with proper orientation on its use, both the World Health Organization (WHO) and the International Federation of Obstetrics and Gynecology, have prepare guidance with the appropriate dosages and route of administration for each indication during pregnancy and the post-partum period [3-6].

The experience of almost 30 years of use of misoprostol in obstetrics and Gynecology has shown that it has become an essential drug to provide appropriate care to women reproductive health needs, up to the point that experienced obstetricians have said that misoprostol is the most important technological innovation for obstetrics practice of the last century.

In order to provide with a short and practical summary of the recommendations for use of misoprostol in Obstetrics and Gynecology, we comment below each of the main indications of this drug in reproductive health.

\section{Induction of labor}

Numerous studies involving thousands of volunteers have shown that misoprostol is a very useful drug for induction of labor with a live fetus. During many years the vaginal route was successfully used, when the dose was limited to $25 \mu \mathrm{g}$. Vaginal misoprostol in doses above 25 mcg four-hourly was more effective than conventional methods of labor induction, but with more uterine hyperstimulation. Lower doses were similar to conventional methods in effectiveness and risks [7]. Increasing the interval to every 6 hours may also reduce the risk of hyperstimulation. More recently, another comprehensive review showed that oral misoprostol, $20 \mu \mathrm{g}$ in solution, was as effective as vaginal misoprostol and results in fewer caesarean sections than vaginal dinoprostone or oxytocin [8]. Considering the risk of ascending infection with the use of vaginal route, evidence supports the use of oral regimens over vaginal regimens. This is especially important in situations where there is higher risk of infection.

Considering that there are reports of uterine rupture after the use of misoprostol for induction of labor in women with C-section scar, it is prudent to contraindicate its use in those cases.

\section{Induction of labor or abortion after fetal demise after 13} weeks of pregnancy

Intrauterine fetal death is a common obstetrics incident, which can lead to maternal complications if left to resolve spontaneously. Induction of labor is not easy considering that this complication usually happens at a time when the cervix is immature, and the uterus is not rich in oxytocin receptors $[9,10]$. Until misoprostol became available, a number of different invasive techniques were use including intraamniotic injection of different substances. When misoprostol appeared, it became an almost magical solution and it was the first indications of misoprostol in obstetrics and Gynecology ever published [11]. Currently, the recommended dosage for fertal demise between 13 and 26 weeks of gestational age is $200 \mu$ g por via vaginal, sublingual or buccal every 4-6 hours; at 27-28 weeks the recommended dosage is $100 \mu \mathrm{g}$ vaginal, sublingual ou buccal every 4 hours and from 28 weeks until, term the dosage is $25 \mu \mathrm{g}$ vaginal every 6 hours or $25 \mu \mathrm{g}$ oral every 2 hours as in induction of labor with live fetus.

${ }^{*}$ Correspondence to: Anibal Faúndes, Department of Obstetrics and Gynecology, Faculty of Medical Science, State University of Campinas, Sao Paulo, Brazil, E-mail: afaundes@uol.com.br

Key words: Misoprostol, termination of pregnancy, incomplete abortion, fetal demise, induction of labor, post-partum hemorrhage

Received: August 20, 2018; Accepted: August 27, 2018; Published: August 31 , 2018 


\section{Missed abortion up to 12 weeks of pregnancy}

The uterine evacuation can be safely done surgically using electric or manual intrauterine aspiration, but it can also be carried out using misoprostol alone in dosages of $800 \mu \mathrm{g}$ vaginal every 3 hours twice or $600 \mu \mathrm{g}$ sublingual every 3 hours, also twice. It should be considered, however, that there is no reason to be limited to repeat the dosages only twice, and in case it does not work after two successive administrations, the dosage can be repeated a third or later time.

\section{Pregnancy termination up to 12 weeks of gestational age}

The recommendation of WHO and FIGO is that the gold standard is the combination of mifepristone and misoprostol, but misoprostol alone can also be used although its effectiveness is not as high and it has more side effects that the combination [5].

Using misoprostol alone, the recommendation is to administer $800 \mu \mathrm{g}$ sublingual every 3 hours, or vaginal or buccal every 3-12 hours, repeating for two or three similar dosages. In most cases the expulsion of the uterine content will occur within six hours after misoprostol administration, although sometimes it makes take more than 24 hours. In order to overcome the pain of the uterine contractions it is appropriate to administer ibuprofen 20 minutes before the first dosage of misoprostol and later as required.

While ibuprofen has been found affective for pain control, paracetamol has not, and should not be used $[11,12]$.

\section{Termination of pregnancy 13 to 26 weeks}

As with earlier pregnancy termination the best results are obtained with the combination of Mifepritone and misoprostol. Using Misoprostol alone the time to complete abortion, much longer than when it is used in combination with mifepristone.

The recommended regimen at $13-24$ weeks is $400 \mu \mathrm{g}$ vaginal, sublingual or buccal, every 3 hours. When the pregnancy is of 25-27 weeks the dosage should be reduced to $200 \mu \mathrm{g}$ vaginal, sublingual or buccal every 4 hours. From 28 weeks: and beyond, the dosage should be reduced to $100 \mu \mathrm{g}$ vaginal, sublingual or buccal every 6 hours [6].

\section{Treatment of incomplete abortion}

Misoprostol is recommended both by WHO and FIGO, for the treatment of incomplete abortion when the size of the uterus correspond to 12 weeks of pregnancy or less the woman is cardiovascularly stable, and the bleeding is not profuse [13].

The recommended dosage is 600 ug orally or 400 ug sublingual [13]. A key element in misoprostol treatment of incomplete abortion is that the results may take several days and that the need for surgical completion should not be guided by ultrasound, but for the clinical symptoms. Surgical evacuation is not required in the absence of pain, fever or bleeding (not simply spotting) [5].

\section{Post-Partum Hemorrhage (PPH)}

Misoprostol has shown to be effective in preventing one the leading causes of maternal deaths in the world, although misoprostol should not replace conventional injectable uterotonics as part of the management of the third stage of labor, when the later are available [6]. The recommended dosage for prevention of Postpartum hemorrhage is of $600 \mu \mathrm{g}$ orally [14].

More recently it has been proposed to use secondary prophylaxis, meaning to use misoprostol only when there is a suspicion of excessive bleeding (approx. $\geq 350 \mathrm{ml}$ blood loss) before reaching the level of a post- partum hemorrhage. In such circumstances a dosage $800 \mu \mathrm{g}$ sublingual, one time, is recommended 1 [15].

Finally, for the treatment of $\mathrm{PPH}$ the recommended dosage is of 800ug sublingual [16].

As misoprostol it is easy to handle and stable at warm temperatures it can be applied by non-physicians in rural areas, as well as in the busy maternity hospital of the third world, with overload of delivering women. Accordingly, there are increasing evidence favoring the use of oral misoprostol for effective prevention of $\mathrm{PPH}$ in areas with low access to facilities and skilled healthcare providers [17].

A review of a number of randomized and non-randomized trials verified that administration of misoprostol was associated with a significant reduction in the incidence of $\mathrm{PPH}$, the use of additional uterotonics and referral for PPH. The conclusion was that distribution of oral misoprostol through frontline health workers is effective in reducing the incidence of $\mathrm{PPH}$ and could contribute to reducing maternal deaths in low-resource settings $[18,19]$.

The main side effects of the use of sublingual misoprostol are shivering and pyrexia, which occasional can be severe. For that reason, it is recommended that the lowest effective dose should be use. There is at least one meta-analysis of direct and adjusted indirect comparisons of the results of randomized trials showing no evidence of any difference in the effectiveness of $600 \mathrm{ug}$ over $400 \mathrm{ug}$ for preventing blood loss $>1000$ $\mathrm{ml}$, while pyrexia was more than twice as common among women who received $>600$ microg as compared with 400 microg of misoprostol. The authors conclusion was that 400 microg of misoprostol were found to be safer and just as effective as 600 microg or higher dosages. In conclusion, misoprostol, correctly applied and indicated, has an enormous potential to reduce complications and deaths of pregnant women and to reduce the cost of their care.

\section{Conclusions}

The above description of the many applications of misoprostol in Obstetrics and Gynecology confirms that misoprostol has improve the results of treatment of a variety of conditions and it is a drug that should always be available for obstetrics and Gynecological practice.

\section{Conflict of interest}

The author have not worked nor receive compensations from the pharmaceutical industry, although AF has been a voluntary advisor of the pharmaceutical Industry Hebron, which produce vaginal misoprostol in Brazil., with the intention of making the drug available in that country.

\section{References}

1. Garris RE, Kirkwood CF (1989) Misoprostol: a prostaglandin E1 analogue. Clin Pharm 8: 627-644. [Crossref]

2. Walt RP (1992) Misoprostol for the treatment of peptic ulcer and antiinflammatorydrug-induced gastroduodenal ulceration. N Engl J Med 327:1575-80.

3. Talaulikar VS, Arulkumaran S (2011) Failed induction of labor: strategies to improve the success rates. Obstet Gynecol Surv 66: 717-728. [Crossref]

4. WHO. Clinical Practice Handbook for Safe Abortion. Geneva: World Health Organization; 2014.

5. WHO. Safe abortion: technical and policy guidance for health systems Geneva: World Health Organization; 2012.

6. Morris JL, Winikoff B, Dabash R, Weeks A, Faundes A, et al. (2017) FIGO's updated recommendations for misoprostol used alone in gynecology and obstetrics. Int $J$ Gynaecol Obstet 138: 363-366. [Crossref] 
7. Hofmeyr GJ, Gülmezoglu AM, Pileggi C (2010) Vaginal misoprostol for cervical ripening and induction of labour. Cochrane Database Syst Rev: CD000941. [Crossref]

8. Alfirevic Z, Aflaifel N, Weeks A (2014) Oral misoprostol for induction of labour. Cochrane Database Syst Rev: CD001338. [Crossref]

9. Fuchs AR, Fuchs F, Husslein P, Soloff MS (1984) Oxytocin receptors in the human uterus during pregnancy and parturition. Am J Obstet Gynecol 150: 734-741. [Crossref]

10. Mariani Neto C, Leão EJ, Barreto EM, Kenj G, De Aquino MM, et al. (1987) [Use of misoprostol for labor induction in stillbirth]. Rev Paul Med 105: 325-328. [Crossref]

11. Matambo J, Moodley J, Chigumadzi P (1999) Analgesia for termination of pregnancy S Afr Med J 89: 816. [Crossref]

12. Cade L, Ashley J (1993) Prophylactic paracetamol for analgesia after vaginal termination of pregnancy. Anaesthesia and Intensive Care, 21:93-96.)

13. Blum J, Winikoff B, Gemzell-Danielsson K, Ho PC, Schiavon R, et al. (2007) Treatment of incomplete abortion and miscarriage with misoprostol. Int J Gynaecol Obstet 99 Suppl 2: S186-189. [Crossref]
14. International Federation Of Gynecology and Obstetrics (2012) Prevention of postpartum hemorrhage with misoprostol. Int J Gynaecol Obstet 119: 213-214. [Crossref]

15. Raghavan S, Geller, Miller H, Goudar SS MC, Anger R, et al. (2015) Misoprostol for primary versus secondary prevention of postpartum haemorrhage: a cluster-randomised non-inferiority community trial. BJOG 123: 120-127. [Crossref]

16. International Federation of Gynecology And Obstetrics (2012) Treatment of postpartum hemorrhage with misoprostol. Int J Gynaecol Obstet 119: 215-216. [Crossref]

17. Tunçalp Ö, Hofmeyr GJ, Gülmezoglu AM (2012) Prostaglandins for preventing postpartum haemorrhage. Cochrane Database Syst Rev: CD000494. [Crossref]

18. Hundley VA1, Avan BI, Sullivan CJ, Graham WJ (2013) Should oral misoprostol be used to prevent postpartum haemorrhage in home-birth settings in low-resource countries? A systematic review of the evidence. BJOG 120:277-85

19. Weeks A, Alfirevic Z, Faúndes A, Hofmeyr GJ, Safar P, et al. (2007) Misoprostol for induction of labor with a live fetus. Int J Gynecol Obstet 99: S194-7.

Copyright: (2018 Faúndes A. This is an open-access article distributed under the terms of the Creative Commons Attribution License, which permits unrestricted use, distribution, and reproduction in any medium, provided the original author and source are credited. 